\title{
A Composite Graph Theoretic Approach to Modeling Landscape Connectivity for Wildlife Movement in Western Canada
}

\author{
M. S. Islam ${ }^{1 *}$ and M. S. Quinn ${ }^{2}$ \\ ${ }^{1}$ Department of Political Science, University of Mississippi, Mississippi 38677, USA \\ ${ }^{2}$ Institute for Environmental Sustainability, Mount Royal University, Calgary, Alberta T3E 6K6, Canada
}

Received 09 October 2020; revised 03 December 2020; accepted 09 February 2021; published online 25 April 2021

\begin{abstract}
Connectivity among the resource patches that provide the wildlife with essential habitat is critical to their survival, but highways and other anthropogenic developments commonly impede wildlife movement. The purpose of this study was to identify suitable locations for highway crossing structures for wildlife movement in a fragmented landscape. Functional connectivity was modeled using human footprint data over a regional landscape in western Canada. A graph-theoretic approach was employed to identify corridors, linkage zones, and the locations where wildlife species cross the highways. A betweenness centrality model was used to compute the shortest path, current flow, and network flow of movements across various landscape lattices. The shortest path model identified a set of geodesic paths to connect the resource patches, the current flow model identified a number of movement zones around the resource patches, and the network flow model identified linkage zones in the network. Finally, a composite of the outputs was used to identify suitable locations for highway crossing for maintaining wildlife movement on the landscape.
\end{abstract}

Keywords: landscape ecology, landscape connectivity, protected area, wildlife movement, graph theory, betweenness centrality

\section{Introduction}

Anthropogenic activities often cause fragmentation of landscapes hindering the movement of wildlife among resource patches that the wildlife requires for survival and growth (Lindenmayer and Fischer, 2007; Hobbs et al., 2008; Giulio et al., 2009). Urban fringe growth is one example that negatively alters native wildlife habitats (Hansen et al., 2005) and road is another that contributes to impairing pathways for wildlife movement by landscape fragmentation (Clevenger and Waltho, 2005; Rudnick et al., 2012; van der Grift et al., 2013; Gurrutxaga and Saura, 2014). The establishment of protected areas (e.g., parks) helps lessen the regional impact of anthropogenic activi-ties and contributes to maintaining biodiversity (Petsas et al., 2020). However, wildlife movement to and from areas near to the protected areas is also impeded by roads and other anthropogenic features that intersect the wildlife pathways and movement zones. To that end, methods to locate and mitigate impaired corridors and linkage zones are essential to designing land-use frameworks, conservation policies, and management practices for wildlife movement as well as the optimal functionality of the protected areas (Swingland and Greenwood, 1983). The purpose of this study is to identify a suitable approach to miti-

${ }^{*}$ Corresponding author. Tel.: +1-(662)-380-0615; fax: +1-(662)-915-7808. E-mail address: sharif_urp02@yahoo.com (M. S. Islam).

ISSN: 2663-6859 print/2663-6867 online

(C) 2021 ISEIS All rights reserved. doi:10.3808/jeil.202100057 gate anthropogenic barriers to reconnect the essential corridors and linkage zones for wildlife movement.

A landscape connectivity approach has been applied to the development of planning and managing conservation strategies; and specifically, to identify corridors and linkage zones that connect fragmented patches of landscapes (Rudnick et al., 2012). Landscape connectivity is a field of inquiry that examines the ecological flow among biotic and abiotic components of a landscape (Merriam, 1984; Taylor et al., 1993). Specifically for wildlife, examining structural and functional connectivity of landscape patches to understand movement, dispersal, and migration has become common among scholars and conservation managers (Tischendorf and Fahrig, 2000). This examination is important to reduce the impact of anthropogenic development on wildlife ecology, and in general, to formulate effective wildlife conservation and management strategies (Carroll et al., 2012; Huber et al., 2012; Mitchell et al., 2013). However, scholars are yet to reach an agreement on the methods to address the issue of species of interest and scale of the landscape analysis (Cadavid-Florez et al., 2020; Petsas et al., 2020).

In connectivity research, scholars generally use the least cost approach and circuit theory to identify corridors and linkage zones (Marrotte and Bowman, 2017; Petsas et al., 2020). The least cost approach assumes the traveler has a complete knowledge of the landscape, and this approach identifies pathways to reduce cost (distance) to reach a destination (Carroll et al., 2012; Rudnick et al., 2012). Circuit theory assumes that the traveler has no knowledge of the entire landscape but the next step of a 
journey, and it models a random walk and identifies a favorable patch (Carroll et al., 2012; Petsas et al., 2020). The least cost metrics generate shortest paths by summing up the minimum costs required to connect the resource patches, and the circuit theoretic models produce current maps based on the probabilistic values of the surface of conductance (Avon and Bergès, 2016; Marrotte and Bowman, 2017; Petsas et al., 2020).

Although these approaches are suitable for network design and land use planning at regional level, effective decision-making for local level conservation management requires the modeling approach capable of addressing finer level details (CadavidFlorez et al., 2020). In designing and planning wildlife corridors, the least cost and current flow approaches produce multiple pathways that require further investigations to identify the most suitable pathways (Gurrutxaga and Saura, 2014; Zhang et al., 2019). In addition, practical implementation of a corridor design requires analysis of the within-patch connectivity and a feasibility study; for instance, installing highway crossing requires analyzing finer level patch characteristics and adjacent site characteristics (van der Grift et al., 2013; Spanowicz and Jaeger, 2019).

To address these problems and to identify strategies for a finer level local conservation management, this study proposes a composite approach where the least cost model, the current flow model, and the network flow model are combined to ascertain a feasible solution. Using a composite approach is beneficial because it addresses multiple species, i.e., species of larger spatial range that likely have more knowledge of the larger landscape and also species of smaller spatial range that likely have less knowledge of the larger landscape. A composite approach also helps to narrow down from multiple options to a set of feasible connectivity solutions. Finally, with a composite approach, the output produced in one method cross validates the output produced in another method. This study applies a social ecological approach to model movement of multiple species and finds that a composite approach is especially effective at local scale where native land is under constant demand of human modification, where land price is high, and where public land is scarce.

\section{Modeling Landscape Connectivity in and around A Protected Area}

Maintenance of landscape connectivity requires an understanding of ecological relationships among heterogeneous components, including the activities of humans, within the landscape (Daily et al., 1997; With et al., 1997; Millenium Ecosystem Assessment, 2003). Protected areas are often designed to reduce the negative impact of human activities, but many species require connected landscapes around a protected area to maintain their dispersal (Government of Canada, 2000; Zhang et al., 2019). Species dispersal involves movements from one resource patch to another (Baguette et al., 2013), and during this movement the species interact with the landscape in terms of speed and direction (Forman and Godron, 1986). As many wildlife species require a substantial area to maintain their life history requirements, they often move through human-dominated land parcels requiring them to cross roads and highways. Their movement can be initiated from anywhere in a resource patch (e.g., native/ natural areas of a landscape), and the movement may also require the use of suboptimal habitat (may be for a short term), especially in the highly altered anthropogenic landscapes $(\mathrm{Hu}-$ bera et al., 2012; Baguette et al., 2013). Anthropogenic developments including roads around a protected area often impede their movement, especially by fragmenting large native patches into multiple smaller patches (Lindenmayer and Fischer, 2007; Hobbs et al., 2008; Giulio et al., 2009). (a) Unweighted directed graph

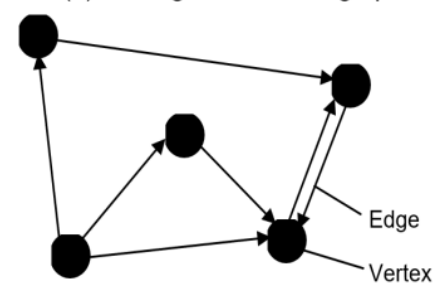

(b) Weighted undirected graph

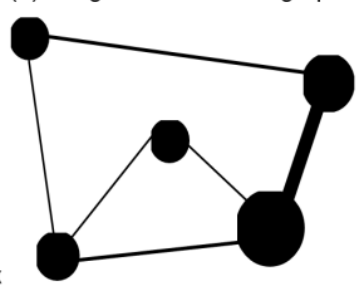

Figure 1. Simple graph: (a) no weights on vertices but expressing directions, (b) different weights on the vertices and edges but expressing no directions.

In order to reconnect fragmented landscapes structurally (spatially), researchers and conservation managers use a variety of conservation measures including road mitigation measures. Among the road mitigation measures, highway crossings are typically installed to facilitate wildlife movement across species dispersal areas. These mitigative structures require significant financial investment. The design and placement of such structures to maximize connectivity and minimize construction cost are critical (Clevenger and Waltho 2005; Olsson et al., 2008; van der Grift et al., 2013). There are many factors that affect mitigation performance including range of human activity, density of crossing structure, and species' perception of access to a crossing (Clevenger and Waltho, 2005). There are also species specific and guild considerations. With regards to that, scholars find that ungulate movement occurs more during the night, animals generally require time to adopt the structure, movement is influenced by traffic volume (Olsson et al., 2008), and so on. In order to address these factors, researchers have developed criteria to design mitigation measures (van der Grift et al., 2013; Gurrutxaga and Saura, 2014). Most important among those measures are: 1. Determining species of interest, 2. Determining scale of study based on the species range, 3. Analyzing the topology of the location around the fragmented area, 4. Considering the effective distance between habitat patches, 5. Considering the distance between other crossing structures, and 6. Taking account of population size of the species.

Understanding structural connectivity is not enough to address dispersal requirements of many species (Baguette et al., 2013). Functional connectivity - the degree to which species are connected to the landscapes for their biological requirements and for their role as a component of the ecosystem - must also be considered. To understand functional connectivity, spatially explicit population models (SEPM) are often employed (Bailey, 2007). However, SEPMs are complex in terms of the variables 
and data required and in terms of the interactions between the model components (Jepsen et al., 2004). SEPM may fail to address unknown parameters that affect the model output (Harrison et al., 1993). A focal species approach identifies linkages for species of interest (often large carnivores with the greatest connectivity area requirements) that act as an umbrella for other species (Bailey, 2007; Koen et al., 2014). However, effective conservation requires comprehensive considerations of wildlife's foraging behavior, movement characteristics, minimum area requirement, and species with requirements that may not fall under the assumptions of the umbrella approach (Baguette et al., 2013; Petsas et al., 2020). Producing a combined connectivity model for multiple focal species might better represent the whole community (Petsas et al., 2020). A multispecies approach is also feasible because it uses a general cost surface for a suit of species, it is more cost effective, and it can offer efficient land-use decision making (Koen et al., 2014).

Researchers commonly use the shortest path, current flow, and network flow metrics in connectivity modeling. The shortest path modeling uses the minimum sum of consecutive cost surfaces to identify the connectivity between two patches (Adriaensen et al., 2003; Brandes and Erlebach, 2005; Rudnick et al., 2012). The cost surface can be any resistance or frictional attribute (e.g., human footprint) for a specific species or wildlife in general (Beier et al., 2009). In the current flow method, probabilistic flow is searched over all possible paths across the landscape (Carroll et al., 2012). The algorithm used in this method is like the electrical-circuit theory applied on the landscape as though it is a conductive surface (Brandes and Erlebach, 2005; Newman, 2005; Rudnick et al., 2012). Similar to the electrical network, a traveler from a source node passes through an intermediate node with a probability proportional to the weight of the corridor it uses to connect the nodes (Carroll et al., 2012). The network flow methods (minimum cost maximum flow and maximum flow) are used to identify user-defined optimal flow from probabilistic possible paths (Carroll et al., 2012). The minimum cost maximum flow approach identifies the nodes that contribute to maximize the flow by keeping the cost as minimum as possible; whereas maximum flow does not consider any cost but maximizes the flow between the source and target nodes (Freeman et al., 1991; Ahuja et al., 1993; Brandes and Erlebach, 2005).

However, the shortest path model is not necessarily an alternative of the current flow model because they produce similar results only when species dispersal range is high (Avon and Bergès, 2016) and when spatial resolution of the modeling is high (Marrotte and Bowman, 2017). Avon and Bergès (2016) find that when dispersal range is over $1,000 \mathrm{~m}$, these two approaches continue to produce similar output, but for small dispersal range, they produce different linkages. They also find that the nodes with high permeable values produce wider shortest paths and lower permeable values produce narrower shortest paths. Shortest path models are sensitive to the number of pixels and Euclidian distance between source and target (Marrotte and Bowman, 2017). Data aggregation - thematic (e.g., aggregation of cost score) or spatial (e.g., using subset of source and target nodes and applying that for all nodes in the landscape)
- tends to influence the current flow model more than the shortest path model (Marrotte and Bowman, 2017). As the number of pixels increases and the level of aggregation increases, these models tend to converge. So, the shortest path model cannot replace the current flow model when the species of interest have small dispersal range and when finer level data representing highly fragmented landscape with important details of private properties are in use. For this type of context, this study proposes a composite approach that combines output from the shortest path models and the current flow models. Additionally, the network flow model is combined to produce a final composite model. A composite approach is useful because the models in it together can balance out the effect of the biases or the shortcomings identified above, i.e., permeability value, grain size of the landscape, Euclidian distance, and the level of aggregation.

Graph theory, combined with the least cost, current flow, and network flow models, produces effective results to help predict the ability of wildlife to move through a landscape (Galpern et al., 2011; Rudnick et al., 2012). It considers a landscape as a set of nodes and edges, and examines the flow of resources across the nodes through the edges (Urban and Keitt, 2001). A graph is a representation of a set of objects and their connectivity (Figure 1). The objects are called vertices or nodes. The links that connect the objects are called edges or arcs. The degree of connectivity is represented by the strength of the edges and that of the objects. With assigning respective landscape attributes to the nodes and edges of a landscape, computer-aided connectivity modeling is conducted to assess the relative importance of each node in a network (Carroll et al., 2012). This approach produces a number of outputs including the identification of critical zones for wildlife activities and shortest paths for the species to move from one resource patch to another. In connectivity modeling, graph theory is used to identify the functional relationship among the nodes (Urban and Keitt, 2001; Zetterberg et al., 2010; Galpern et al., 2011). Such modeling can contribute to understanding qualitative aspects of landscape planning and management that are necessary for effective decision making on mitigation measures (Scolozzi and Geneletti, 2012).

In this study, landscape connectivity is modeled to identify corridors and linkage zones for relatively large, mobile mammals in and around a protected area, Glenbow Ranch Provincial Park, in western Canada. Given the discussion above, this study employs a multispecies approach and adopts a study area relevant to the dispersal range of the species in the protected area. To do the modeling, the following operationalization and assumptions are used: Corridors are areas that species use to move from one favorable patch to another. Linkage zones are wider than the corridors and also provide animals with resources for a temporary stay to maintain inter-zonal connectivity. To identify corridors and linkage zones, the researchers assume that wildlife movement can be initiated anywhere in the landscape and movement can freely occur across the natural landscapes (Huber et al., 2012). Among human-dominated landscapes, roads, mining sites, and settlements are examples of potential barriers (or friction) to movement. Wildlife species move across favorable land parcels, and distance remains their 
Table 1. Habitat Permeability and Cost for Wildlife Movement

\begin{tabular}{|c|c|c|c|}
\hline Land Use Category (\% of study area) & Foot Print Name & Permeability Score & Cost Score \\
\hline Native/natural (40.91) & - & 100 & 0 \\
\hline \multirow[t]{3}{*}{ Urban \& rural features (16.90) } & Urban & 20 & 80 \\
\hline & Rural (Residential/Industrial) & 40 & 60 \\
\hline & Other disturbed vegetation (urban/rural greenspace) & 70 & 30 \\
\hline \multirow{4}{*}{$\begin{array}{l}\text { Industrial \& resource extraction features } \\
(1.41)\end{array}$} & High density livestock operation & 0 & 100 \\
\hline & Industrial site rural & 0 & 100 \\
\hline & Mine site & 0 & 100 \\
\hline & Well site & 0 & 100 \\
\hline \multirow[t]{2}{*}{ Hard linear features (1.71) } & Rail and hard surface & 0 & 100 \\
\hline & Road and hard surface & 0 & 100 \\
\hline \multirow[t]{3}{*}{ Soft linear features $(0.57)$} & Pipeline & 10 & 90 \\
\hline & Transmission line & 20 & 80 \\
\hline & Seismic line & 50 & 50 \\
\hline \multirow{3}{*}{$\begin{array}{l}\text { Vegetated roads, verges, and ditches } \\
\text { (3.80) }\end{array}$} & Road/trail (vegetated) & 80 & 20 \\
\hline & Rail and vegetated verge & 60 & 40 \\
\hline & Road and vegetated verge & 60 & 40 \\
\hline \multirow[t]{4}{*}{ Human-created water bodies $(0.68)$} & Reservoirs & 50 & 50 \\
\hline & Borrow-pits/dugouts/sumps & 0 & 100 \\
\hline & Municipal (water and sewage) & 0 & 100 \\
\hline & Canals & 60 & 40 \\
\hline Cultivation (33.86) & Cultivation (crop/pasture/bare ground) & 50 & 50 \\
\hline Managed forest $(0.16)$ & Cut blocks & 70 & 30 \\
\hline
\end{tabular}

cost function (Huber et al., 2012). If the disperser species have knowledge about the landscape, they use shortest paths to move across source patches and target patches (Huber et al., 2012). On the other hand, if the dispersers do not have knowledge of the landscape, they attempt to find the favorable patch in the next step of a journey (Huber et al., 2012). In a fragmented landscape, unfavorable patches can hinder species movement.

\section{Methods}

\subsection{Context}

The research was situated within the Calgary metropolitan area (i.e., Calgary region) of Alberta, Canada. The study area was bounded by three major highways and one primary road viz., Highway \#567 in the north, Highway \#1 in the south, Bearspaw Road in the east and Highway \#22 in the west. The study area was 33,405 ha and is situated within three management jurisdictions: Rocky View 44 Municipal District, Town of Cochrane, and Glenbow Ranch Provincial Park (GRPP). The core of the study area was the GRPP, which is located northwest of the city of Calgary on the south side of Highway \#1A between Cochrane and Calgary. Situated in a location surrounded by developed or developing residential area with some agriculture, GRPP has a strategic role to play in maintaining regional biodiversity. GRPP is also a popular recreational area because it is only a $15 \sim 60$ minutes' drive from any part of Calgary or Cochrane. The park has an area of 1,334 ha consisting of rolling foothills with forested parklands and native fescue grasslands. The Bow River flows along the southern side of the park while the Highway \#1A runs along the northern side. The surrounding land-use of the park is characterized by sporadically developed residential areas and farmlands. The expected land-use trajectory is for greater urban and rural residential development in the Calgary-Cochrane corridor.

\subsection{Data}

For modeling, this study utilizes human footprint land-use data (Alberta Biodiversity Monitoring Institute, 2010) where each parcel of land represents the degree of disturbance for anthropogenic use in terms of transformation of naturalness. The naturalness of the landscape parcels is self-explanatory from the category it represents; but for quantification, an expert rated score is used for making a ranking of the landscape features (Table 1). The group of experts consisted of professors and post-doctoral fellows from the School of Architecture, Planning and Landscape at the University of Calgary and practitioners of ecological applications from Miistakis Institute (www.rockies.ca). Land-use types that were completely changed into a different type, and where the native ecosystem was totally transformed received a permeability score of zero and cost score of 100 (see Koen et al. (2014) for similar cost scoring method). For instance, industrial \& resource extraction features and hard linear features have no permeability for wildlife movement. The least transformed was native/natural features and the highest transformed features included highways, mining sites, and the like. The value of 'zero' for cost and permeability was replaced by 'one' in the Connectivity Analysis Toolkits (CAT), the computer program that was used for computation, to avoid antifriction of the flow over the landscape surface. Two types of costs were considered for species movement: distance and the level of transformation. In the modeling, the landscape data were converted into equal sized (four hectares each) hexagonal 
nodes, and each node was assigned with a permeability and cost score it represents. The hexagons that fell at the edge of a polygon received the score from the polygon that contained the greater portion of that hexagon. In the study area, there were 8,362 hexagons. The connectivity modeling was conducted for two sets of source and target data. One set was a randomly generated 50 hexagons and another was every hexagon in the study area. Both sets were used for shortest path approach and current flow approach. Because of computational infeasibility, only randomly selected nodes were used for the minimum cost maximum flow and maximum flow approaches.

\subsection{Computer Program and Metrics Used}

The computer program, Connectivity Analysis Toolkits (CAT) developed by Carroll et al. (2012) (www.klamathconservation.org), was used in this study to run the shortest path, current flow, and network flow models for identifying predictive species dispersal. The shortest path method was employed to identify corridors, and the minimum cost maximum flow method to identify linkage zones in the network. As the shortest path method assumes that species have a perfect knowledge of the landscape, the shortest path method connects source and target patches considering distance as the cost function. The minimum cost maximum flow method identifies corridors that maximize the flow between the source and target patches by keeping the cost (distance and resistance) as low as possible. With the current flow and maximum flow methods, the zones where the species originate are identified. As the current flow method assumes that dispersers have no knowledge of the path one step ahead of them (Newman, 2005), this model identifies a set of zones consisting of favorable land parcels with different levels of conductance. The maximum flow model identifies the zones that contribute to maximize the flow of species movement assuming that the species do not have any knowledge of the barriers. Finally, the outputs from these four metrics are combined and compared to assess landscape connectivity for the study area.

\subsection{Graph Theoretic Betweenness Centrality}

A graph theoretic betweenness centrality measure was applied in this study to predict corridors and matrices for wildlife movement. Betweenness centrality measures take account of the relative importance of a node to appear in between a source and a target node. The model provided a betweenness centrality value for each node for each method (for more on the graph theoretic metrics and centrality values, see Brandes and Erlebach (2005), Newman (2005), and Carroll et al. (2012)). With the shortest path method, each node produced a value based on the count of the shortest paths where that particular node is involved divided by the total shortest paths in the network as in Equation (1) (Brandes and Erlebach, 2005). That is why the value of a node for subset method (50 source and target nodes) was greater than that for an all-pair method (8,362 source and target nodes) (Table 2).

The equation to compute shortest path betweeness centrality $C_{B}$ for a node $v$ is:
$C_{B}(v)=\sum_{s, t \in N} \frac{\sigma(s, t \mid v)}{\sigma(s, t)}$

where $N$ is the set of nodes, $\sigma(s, t)$ ( $s=$ source, $t=$ target $)$ is the number of all shortest paths, and $\sigma(s, t \mid v)$ is the number of those paths passing through the node $v$ other than $(s, t)$ such that $s=t, \sigma(s, t)=1, \sigma(s, t \mid v)=0$, or $v \in s, t$.

In the current flow model, betweenness centrality of a node is the net number of times that a random walk starting at the source and ending at the target passed through that node, averaged over all sources and targets as in Equation (2) (Brandes and Erlebach, 2005; Newman, 2005). Similar to the shortest path, the value of subset centrality for the current flow was greater than the value of all-pair centrality. The subset models closely matched the all-pairs models. The subset methods and all-pairs methods were strongly correlated: $r^{2}=0.61$ and 0.65 for the shortest path and current flow model, respecttively. The net flow of random walks through a vertex, $i$ in the network is computed by the following equation (Brandes and Erlebach, 2005):

$b_{i}=\frac{\sum_{s<t} I_{i}(s t)}{\frac{1}{2} n(n-1)}$

where $n=$ number of nodes involved as source $(s)$ and target $(t)$, and $I_{i}(s t)=$ the flow of random walk starting at $s$ and ending at $t$ through node $i$ :

$I_{i}(s t)=\frac{1}{2} \sum_{j} A_{i j}\left|V_{i}(s t)-V_{j}(s t)\right|$

where $A_{i j}=$ Adjacency matrix between $i$ and $j$, and $V_{i}-V_{j}=$ the net flow of the random walk along the edge from $j$ to $i$ :

$V=\left(D_{t}-A_{t}\right)^{-1} \times s$

where $D_{t}=$ degree matrix, $A_{t}=$ adjacency matrix, and $s=$ a source vector with the following elements: $s_{i}=+1$ for $i=s,-1$ for $i=t, 0$ otherwise.

In the network flow models (the minimum cost maximum flow and the maximum flow), the amount of total flow (i.e., capacity or permeability score) that must go through a node is divided by the maximum flow between a source and a target (Freeman et al., 1991; Brandes and Erlebach, 2005). In the minimum cost maximum flow, each node was given a cost value (e.g., human footprint score). In the maximum flow model, there was no cost for a node, but the model maximized the flow based on permeability score. Maximum flow betweenness centrality for a vertex $C_{m f}(v)$ is calculated by the following Equation (5). For minimum cost maximum flow, betweenness centrality is computed with the same equation but each edge has a nonnegative cost value and a maximum capacity (Brandes and Erlebach, 2005): 
Table 2. Ranking Method for Centrality Values of the Modeling Outputs

\begin{tabular}{|c|c|c|c|c|c|c|}
\hline Rank (natural break) & $\begin{array}{l}\text { Shortest Path } \\
\text { Subset } \\
\text { Centrality }\end{array}$ & $\begin{array}{l}\text { Shortest Path } \\
\text { All-Pair } \\
\text { Centrality }\end{array}$ & $\begin{array}{l}\text { Current Flow } \\
\text { Subset } \\
\text { Centrality } \\
\end{array}$ & $\begin{array}{l}\text { Current Flow All- } \\
\text { Pair Centrality }\end{array}$ & $\begin{array}{l}\text { Minimum Cost } \\
\text { Maximum Flow } \\
\text { Subset Centrality }\end{array}$ & $\begin{array}{l}\text { Maximum Flow } \\
\text { Subset Centrality }\end{array}$ \\
\hline None/very low & 0 & $0 \sim 0.005154$ & $\begin{array}{l}0.070720 \sim \\
7.492971\end{array}$ & $\begin{array}{l}0.000143 \sim \\
0.005878\end{array}$ & $0 \sim 34369$ & $0 \sim 6926$ \\
\hline Low & $\begin{array}{l}0.000000001 \sim \\
19.6093750\end{array}$ & $\begin{array}{l}0.005155 \sim \\
0.015546\end{array}$ & $\begin{array}{l}7.492972 \sim \\
12.218765\end{array}$ & $\begin{array}{l}0.005879 \sim \\
0.008937\end{array}$ & $34370 \sim 108160$ & $6927 \sim 42589$ \\
\hline Moderate & $\begin{array}{l}19.6093751 \sim \\
36.4548340\end{array}$ & $\begin{array}{l}0.015547 \sim \\
0.031402\end{array}$ & $\begin{array}{l}12.218766 \sim \\
17.52552\end{array}$ & $\begin{array}{l}0.008938 \sim \\
0.011295\end{array}$ & $108161 \sim 212366$ & $42590 \sim 89488$ \\
\hline High & $\begin{array}{l}36.4548341 \sim \\
65.5061035\end{array}$ & $\begin{array}{l}0.031403 \sim \\
0.054535\end{array}$ & $\begin{array}{l}17.52553 \sim \\
25.884816\end{array}$ & $\begin{array}{l}0.011296 \sim \\
0.013914\end{array}$ & $212367 \sim 384874$ & $89489 \sim 149550$ \\
\hline Very high & $\begin{array}{l}65.5061036 \sim \\
130.0\end{array}$ & $\begin{array}{l}0.054536 \sim \\
0.123137\end{array}$ & $\begin{array}{l}25.884817 \sim \\
49.323326\end{array}$ & $\begin{array}{l}0.013915 \sim \\
0.018833\end{array}$ & $384875 \sim 851214$ & $149551 \sim 647710$ \\
\hline
\end{tabular}

$$
C_{m f}(v)=\sum_{\substack{s, t \in N \\ v \neq s, t \\ f_{s t}>0}} \frac{f_{s t}(v)}{f_{s t}}
$$

where $f_{s t}(v)=$ the amount of flow which must go through $v$, and $f_{s t}=$ the maximum flow between $s$ and $t$ in the network with respect to capacity constraints and balance conditions.

With the above equations, the centrality values for each metric was derived. For ease of understanding, the centrality values were categorized into five groups ranging from 'very low' to 'very high' (Table 2). Jenks natural breaks method (Jenks, 1967) was used to group the data. In Jenks natural breaks, the deviation within a class is kept as low as possible from the class mean; whereas, deviation from each class mean is kept as maximum as possible. To analyze connectivity of a node, its centrality value was examined vis-à-vis the landscape feature it represents. For spatial analysis, the attributes of the landscape feature were recorded on the centroid of a node - a centroid falling in a particular GIS polygon received the attributes of the respective landscape features of that polygon.

\subsection{Model Validation}

To validate the model outputs, road-killed wildlife data and remote camera wildlife data collected in 2013 2014 were used. The road-killed wildlife data was a one-year record of road-killed species on Highway \#1A and Highway 22 of Alberta. To record the road-killed data, the highways were divided into one-kilometer segments and the road-killed information for each segment was entered. Then, the researchers observed whether the segments that were crossed by the modelled corridors and linkage zones were also used by the wildlife species (for more on road-kill studies, see Koen et al. (2014) and Girardet et al. (2015)). The minimum cost maximum flow model best corresponded to the road-kill data. There was $35 \%, 43 \%$, and $63 \%$ of highway segments that had a road-kill record corresponded to the subset based shortest paths, the all-pair based shortest paths, and the subset based minimum cost maximum flow linkage zones, respectively. Because of the limitation of historical road-killed data, the percentage of correspondence was low. Secondly, to validate connectivity results for within the park, wildlife camera data was used that came from 41 cam- eras (Reconyx) installed in the GRPP. The frequency of species sightings was divided by the number of days of camera operation to get a relative frequency. After that, the data was extrapolated based on an ArcGIS inverse distance weighted (IDW) method. The IDW was used assuming that sightings were likely to occur more around the locations of higher sightings than the locations that were farther away from the higher sighting locations. Comparing the extrapolated layer of species sightings with the modeling outputs, the researchers found that the direction of the species corresponded to the model based direction of the corridors. Again, the modeled corridors were found to be connecting all the high-frequency camera locations in the park.

\section{Results}

Each model in this study connected the source and target nodes in the network using either shortest paths or optimal zones (Figure 2). The shortest path model identified several geodesic shortest paths basically connecting the highly permeable landscape features. The current flow model identified a number of conductive zones basically occurring around the shortest paths, similar to what Carroll et al. (2012) found. Both in subset pairs and all-pairs, shortest paths connected the strong centrality zones produced by the current flow method. The minimum cost maximum flow model identified a number of paths wider than that identified by the shortest path model connecting the highly permeable areas (e.g., native/natural areas) in the network. The shortest paths were found to be traveling through the middle of the minimum cost maximum flow paths. The maximum flow model maximized the flow between the source and target nodes. Similar to the current flow model, the maximum flow model produced a number of zones of different levels of centrality values. The shortest paths connected not only the current flow conductive zones but also the strong centrality nodes identified by the maximum flow model. The zones identified by the current flow model were also connected by the wider paths identified by the minimum cost maximum flow model. As such, the outputs produced by these four metrics were complementary to each other.

However, there were also some noteworthy differences. If the wider paths identified by the minimum cost maximum flow model is considered as single paths, they connected the current 
flow zones using fewer amounts of paths than the shortest paths. The difference of outputs between the minimum cost maximum flow and the maximum flow was also significant. With presence of cost, the minimum cost maximum flow method identified narrow strips (of course, wider than the shortest paths). In contrast, with absence of cost, the maximum flow model identified a number of zones that fell in between the source and target nodes to maximize the flow. Unlike the current flow, the maximum flow identified the zones that were not necessarily concentrated around the native/natural areas. (a) Shortest path

(c) Minimum cost maximum flow

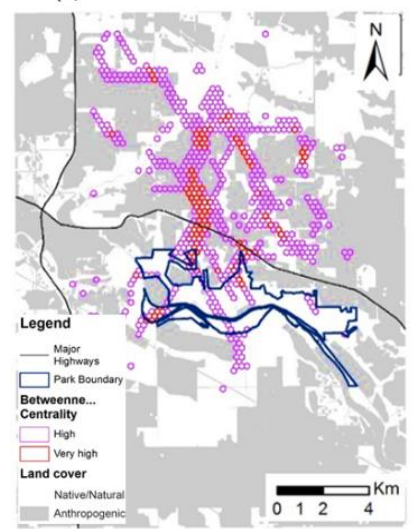

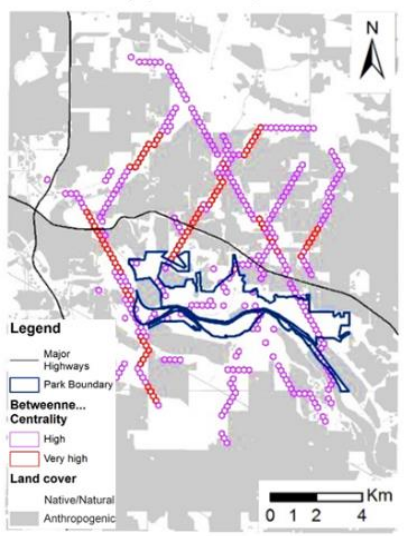

(b) Current flow

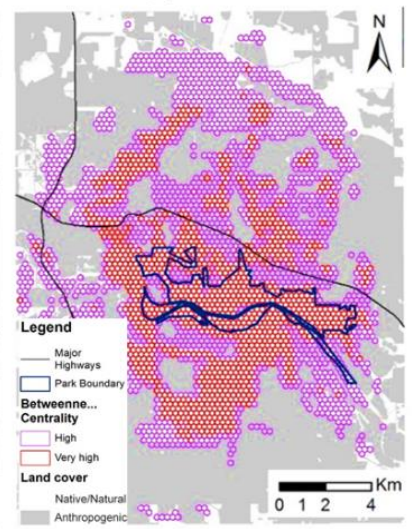

(d) Maximum flow

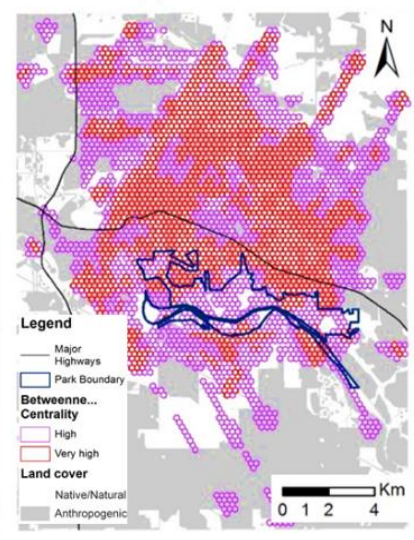

Figure 2. Results of connectivity modeling: (a) identified a set of geodesic corridors, (b) identified zones with multiple degrees of permeability, (c) identified wider paths which are defined as linkage zones, and (d) identified permeable zones without considering any resistance.

The results that each model produced separately helps understanding important aspects of landscape connectivity (Table 3). For example, to connect the native/natural features in the study area, the shortest path subset model identified $5.34 \%$ of nodes as corridors that had high or very high centrality. Of this $5.34 \%$, $4.48 \%$ fell under native/natural features and the rest fell under anthropogenic features. It implies that $0.86 \%$ anthropogenic land areas (i.e., $287.3 \mathrm{ha}$ ) will have to be taken under consideration to establish connectivity within the study area. This land amount is $3.12 \%$ identified by the minimum cost maximum flow method; however, this method identified linkage zones, which are wider than the corridors. Again, the current flow subset model included $18.57 \%$ anthropogenic land area as the areas that had moderate to very high level of conductance; and two fragmenting roads (Highway \#1A and Highway \#766) were included within the conductance zones, implying that highways and other human dominated lands are included within the species movement zones. Finally, the maximum flow model considered the cost to be the same for all nodes; therefore, identified a hypothetical situation where there were no barriers. In the maximum flow method, a very high level of centrality was identified to be concentrated more on the northern side of the Highway \#1A, implying that if there were no cost (say, no highway), wildlife movement would have occurred more on the northern side of GRPP.

In order to delineate the zones of wildlife movement around GRPP and identify existing barriers, the researchers examined the landscape around GRPP. Ungulates and meso carnivores such as mule deer, white-tailed deer, moose, coyote, and red fox (which are native to the study area) have an average home range between one and five sq. $\mathrm{km}$, and a seasonal range between one and $15 \mathrm{sq}$. km to meet their annual life history requirements (Peterson, 1950; Lynch and Morgantini, 1984; Bekoff and Wells, 1986; Gerlach et al., 1994; Cavallini, 1996; Walter et al., 2009). Based on this information, two-kilometer buffer rings were established around GRPP to identify where the barriers of movement were most acute. Highway \#1A was located within the inner $2 \mathrm{~km}$ buffer. The edge of Calgary and Cochrane fell in the second ring (i.e., within four $\mathrm{km}$ ) of the buffer from GRPP. The Trans-Canada highway is located within six to eight $\mathrm{km}$ distance from GRPP. This analysis implies that, there were major barriers to species movement on every side of GRPP. Thus, highway crossing remains as one of the critical factors for maintaining species movement from south to north in the study area. Highway \#1A dissects the study area into an area of $152.2 \mathrm{sq} . \mathrm{km}$ in the north and an area of 168.9 sq. km. up to Highway \#1 in the south. Species have an area of $142.7 \mathrm{sq}$. km. in the south to move without facing any barrier like highways. In the north, however, Highway \#1A is within two kilometers and the species have to face this major barrier to move to/from north. Maintaining connectivity to the northern side for the species of GRPP requires crossing the Highway \#1A. Therefore, it was necessary to take mitigation measures to establish connectivity between the areas across the highway on the north.

There were a number of corridors and linkage zones identified by each model that passed through Highway \#1A. The shortest path, minimum cost maximum flow, and current flow models were applied to identify locations for possible highway mitigation. To avoid redundancy of the nodal centrality value, only 'very high' nodal centrality was used to look where the associated nodes connected the areas across Highway \#1A. Two very 'high-centrality' shortest paths and another two very high-centrality linkage zones were identified that the minimum cost maximum flow model generated. In addition, the very high conductivity current flow zones that exceeded the boundary of GRPP were also found to have passed beyond Highway \#1A on the northern side (also, the Bow River on the southern side). There were a number of locations identified where the current 
Table 3. Summary of Comparison among Different Modeling Approaches

\begin{tabular}{|c|c|c|c|c|}
\hline Parameters & Shortest Path & Current Flow & $\begin{array}{l}\text { Minimum Cost } \\
\text { Maximum Flow }\end{array}$ & Maximum Flow \\
\hline Concept & $\begin{array}{l}\text { Geodesic shortest paths among } \\
\text { resource patches }\end{array}$ & $\begin{array}{l}\text { Conductance of resource } \\
\text { patches }\end{array}$ & $\begin{array}{l}\text { Maximization of } \\
\text { movement flow where } \\
\text { cost is involved }\end{array}$ & $\begin{array}{l}\text { Maximization of } \\
\text { movement flow where } \\
\text { cost is not involved }\end{array}$ \\
\hline Output & Corridors & Conductive zones & Linkage zones & $\begin{array}{l}\text { Hypothetical zones if } \\
\text { there were no barriers }\end{array}$ \\
\hline Assumption & $\begin{array}{l}\text { Species have perfect knowledge } \\
\text { on landscape patches }\end{array}$ & $\begin{array}{l}\text { Species have no knowledge } \\
\text { on landscape except the } \\
\text { next step in a journey }\end{array}$ & $\begin{array}{l}\text { Species can avoid the } \\
\text { barriers }\end{array}$ & $\begin{array}{l}\text { Species do not have } \\
\text { knowledge on barriers }\end{array}$ \\
\hline $\begin{array}{l}\text { Connectivity } \\
\text { Source-target }\end{array}$ & $\begin{array}{l}\text { - Native/natural area } \\
\text { - All area }\end{array}$ & $\begin{array}{l}\text { - Native/natural area } \\
\text { - All area }\end{array}$ & - Native/natural area & - Native/natural area \\
\hline $\begin{array}{l}\text { Result: Highway } \\
\text { \#1A Perspective }\end{array}$ & $\begin{array}{l}\text { Multiple single paths crossed } \\
\text { the highway to connect the } \\
\text { northern side to the southern } \\
\text { side }\end{array}$ & $\begin{array}{l}\text { Identified a number of high } \\
\text { conductive zones that } \\
\text { included the highway }\end{array}$ & $\begin{array}{l}\text { Multiple wider paths } \\
\text { crossed the highway to } \\
\text { maximize the flow of } \\
\text { movement }\end{array}$ & $\begin{array}{l}\text { Identified the highway } \\
\text { as to running by the } \\
\text { maximum flow zones if } \\
\text { there were no barriers }\end{array}$ \\
\hline $\begin{array}{l}\text { Result: GRPP } \\
\text { Perspective }\end{array}$ & $\begin{array}{l}\text { Several shortest paths passed } \\
\text { through the GRPP to connect } \\
\text { the landscapes across the park }\end{array}$ & $\begin{array}{l}\text { Almost the entire park was } \\
\text { identified as highly } \\
\text { conductive for wildlife } \\
\text { movement }\end{array}$ & $\begin{array}{l}\text { Critical linkage corridors } \\
\text { identified within the park } \\
\text { that were commensurate } \\
\text { to the shortest path }\end{array}$ & $\begin{array}{l}\text { High centrality } \\
\text { maximum flow zones } \\
\text { occurred substantially } \\
\text { outside the GRPP }\end{array}$ \\
\hline $\begin{array}{l}\text { Discussion: } \\
\text { Implementation } \\
\text { Perspective }\end{array}$ & $\begin{array}{l}\text { Small number of geodesic paths } \\
\text { are created; useful for corridor } \\
\text { designing and highway } \\
\text { mitigation planning }\end{array}$ & $\begin{array}{l}\text { Priority zones are created } \\
\text { around resource patches; } \\
\text { thus, contributing to } \\
\text { making long-term } \\
\text { conservation strategies }\end{array}$ & $\begin{array}{l}\text { Wider corridors leave } \\
\text { options for the planners } \\
\text { in implementing a } \\
\text { practical solution }\end{array}$ & $\begin{array}{l}\text { Complementary to } \\
\text { current flow method to } \\
\text { prioritize among } \\
\text { conservation zones }\end{array}$ \\
\hline
\end{tabular}

flow ‘very high’ conductivity crossed Highway \#1A (Figure 2).

From the anlysis three sites were identified for the installation of highway crossing structure where at least two methods produced the same result (Figure 3). In Option \#1 (box marked in Figure 3), current flow zones passed across Highway \#1A and so did a shortest path. The advantageous side of Option \#1 is that it connected a narrow vegetative strip that is directed to the Big-Hill Springs Provincial Park (another small protected area in the region). However, there were a number of issues with this option: first, this path passed through the middle of settlements in the town of Cocharane; second, to connect with GRPP, this path had to cross the Bow River twice (once moving across the southern side of the river and again moving back to GRPP passing across the river) because of the adjacent settlemets in the eastern side of the path; third, there were private lands and settlements along the narrow vegetative strip near Big-Hill Springs Provincial Park; and fourth, this path was not validated by the road-killed wildlife data. In Option \#2, all three modeling approaches provided a common result. This path runs along the Glenbow Road on the northern side and Range Road 35 on the southern side of Highway \#1A. The path in Option \#2, avoided the private lands and also connected most of the native patches in the northern side of the study area, including the vegetative strip that directed toward the Big-Hill Springs Provincial Park. The associated highway segment had 17\% roadkill records of all the roadkill records found on Highway \#1A. In Option \#3, the current flow and minimum cost maximum flow model generated the same result. This Path runs by the Glendale Road and is linked to both the north-western and north-eastern part of the landscape. The associated highway segment with Option \#3 was also found to have $11 \%$ roadkilled record on Highway \#1A. Among the three highway mitigation options, Option \#2 provided the most robust result in terms of modeling result and validation correspondence. Option \#3 provided the second most robust result, followed by Option \#1.

In order to determine the priority of wildlife pathways that passed through GRPP to connect the landscapes around GRPP, the very high centrality value of nodes for the shortest path method and the minimum cost maximum flow method were used. Combinedly with these two methods, there were four paths identified that passed through GRPP. Among the four identified paths, two were found to have high correspondence with the camerabased sightings. These two paths connected the entire landscape around GRPP with GRPP. These two paths are connected to the highway mitigation Option \#2 and Option \#3.

\section{Discussion}

In this study the current state of habitat fragmentation was assessed from the perspective of movement of large mammals. Because the study area is situated between a large city and a rapidly growing town, the continued development pressure in the Calgary-Cochrane corridor will likely put a significant strain on the functional connectivity for many species and ecological processes. Glenbow Ranch Provincial Park is located within such a regional area where it can work as a 'source' for the wildlife species by providing sufficient conditions for their breeding and survival. In the modeling outputs, the entire GRPP was identified as 'very conductive' zone for wildlife movement in the study area. With the current flow all pair method, very high conductive zones were found for $15.49 \%$ native/natural land area whereas GRPP itself has $9.51 \%$ native/natural land 
area in the study area. Moreover, other 'high' to 'very high' conductive zones were identified to be mostly located around GRPP. On the other hand, the ungulates and meso-carnivores that inhabit GRPP have a seasonal range larger than this protected area. If they become isolated in the GRPP, their survival will be under threat. The remaining native patches are dispersedly located but connectivity among them is necessary to allow the species to maintain their movements (Zhang et al., 2019; Cadavid-Florez et al., 2020).

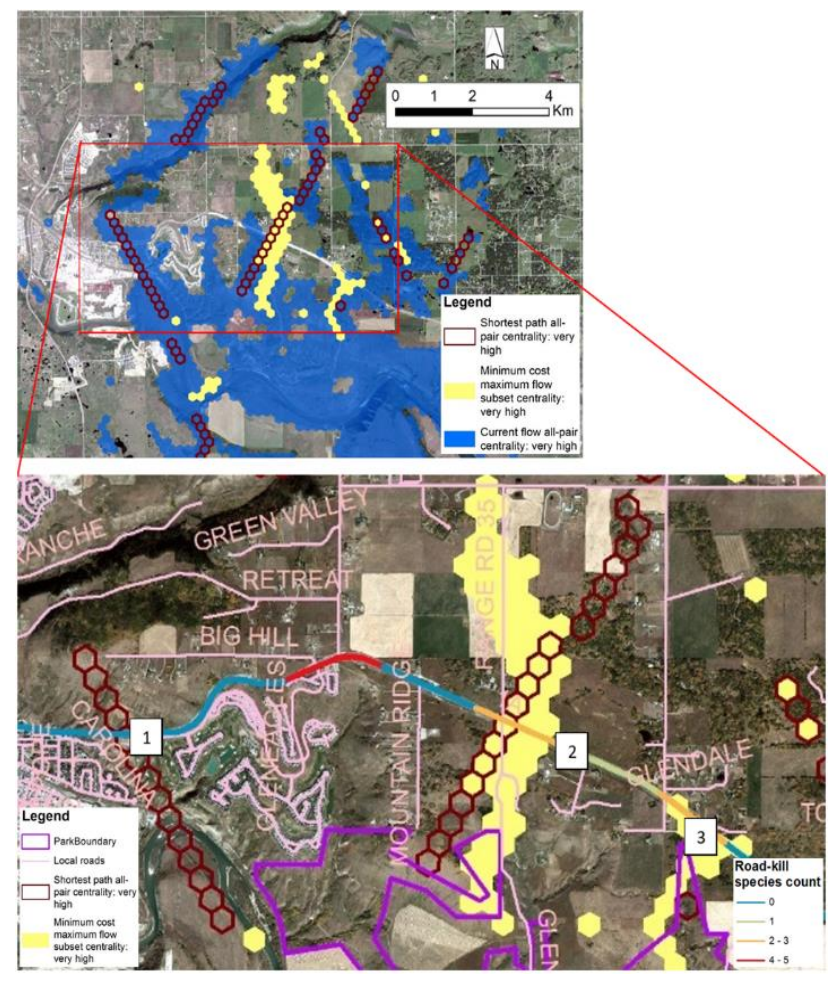

Figure 3. Highway crossing options for wildlife movement.

Our modeling approaches focused on functional connectivity to maintain the ecological integrity of a protected area (Tischendorf and Fahrig, 2000). Modeling approaches, such as the ones in this study, that look at connecting all possible patches are regarded in the literature as efficient because the models that identify the linkages among fixed termini possibly miss out other potential linkage points (Huber et al., 2012). In this study, two types of connectivity modeling were exercised: one focusing on connecting the native areas based on selected random points, and the other connecting all nodes in the network based on capacity (permeability) and cost (human footprint). As such, this study identified corridors and linkage zones to connect landscapes that are important from the functional point of view. In addition, a number of potential connectivity mitigation options were identified from which structural connectivity can be established to maintain the overall functional connectivity of the study area (Baguette et al., 2013). The results presented in these options provided valuable input into planning for both highway mitigation options and collaborative opportunities to maintain regional connectivity (i.e., working with private landowners).
In this study, human footprint data was used to model landscape connectivity for relatively large and mobile mammals. A species-specific modeling was not conducted because of the unavailability of the species-specific habitat data. A landscape with more diverse species requires species-specific connectivity modeling, which, however, was not the case in the current study. No habitat suitability modeling was used but the permeability score of landscape lattices used in this study served the purpose to model multispecies movement on the landscape. In this research, land value was not considered as a cost factor. A landscape with more private lands might require considering the land price as a cost function in the modeling. Modeling to provide decision support for complex environmental problems (such as maintaining landscape connectivity) is characterized by significant uncertainty (Uusitalo et al., 2015). The approach and results presented here make the modelling assumptions transparent and minimize uncertainty through the use of comparing multiple model outputs, the use of expert opinion, and validation with field data.

This research was conducted for an area of 33,405 hectares, but similar modeling can be conducted for larger and smaller landscapes. The study area falls under Rocky View Municipal District (MD) and partly under the Town of Cochrane of Alberta. The management options identified in this research will be complementary to the interventions by the municipal authorities. The Calgary Regional Partnership (CRP) that works for collaborative actions on land \& water use, urban growth, and shared infrastructure (Calgary Regional Partnership, 2012) will benefit from this research because Rocky View MD is one of the member municipalities of CRP. Moreover, CRP can benefit from the method and result of this study through the related research being conducted by Quinn et al. (2014). This research is aligned with the strategic plan of South Saskatchewan Regional Plan (SSRP) that aims to maintain biodiversity and ecosystem health (Government of Alberta, 2014). Implementing the recommendations proposed in this research will be complementary to the implementation planning of SSRP.

\section{Conclusions}

This study used a composite of the shortest path, current flow, and network flow models to examine landscape connectivity for wildlife movement in a highly fragmented landscape located in between two rapidly growing urban areas. The current study addressed how to avoid biases that might arise from a single model approach. The shortest path model produces geodesic paths biased by the Euclidian distance, and the current flow model produces conductive zones biased by the level of data aggregation (Marrotte and Bowman, 2017). These biases may cause land-use policymaking inefficient and implementing mitigation measures infeasible, especially for a highly fragmented landscape. This study presented a practical application of how to use a composite approach for a study area that is under tremendous development pressure for urbanization. The approach in this study demonstrates that the shortest path model is not an alternative of the current flow model (Avon and Bergès, 2016). Rather, these two models are complementary to each 
other as the geodesic paths identified by the shortest path model tends to connect the zones of conductance identified by the current flow model. Again, the minimum cost maximum flow model that produces wider paths is also complementary to the shortest path model because the shortest paths of the latter tend to run through the middle of the wider paths (linkage zones) of the former. These wider paths also tend to connect more conductance zones, some of which are missed by the shortest paths.

A composite approach also benefits finding a suitable mitigation measures across the fragmenting barriers (e.g., roads). Each modeling approach creates a set of options in terms of identifying the site for installing highway crossing. The shortest path model connects the fragmented land parcels with geodesic paths, but such paths can be misleading for a highly fragmented landscape; especially for the one that has much private lands. On the other hand, the current flow model creates zones of probable wildlife movements but determining the site for highway crossing requires looking also at the shortest paths that connect those zones. The minimum cost maximum flow model produces wider paths, which need further specification in order to practically identify the sites for the installation of crossing structures. By combining these models, this study identified the most suitable sites based on their best corresponddence to all three models. This study maintained that the sites that were identified by the all three models and that corresponded to the road-kill data were the most suitable sites for installing highway crossings.

In terms of scope of this research, although it was conducted to study landscape connectivity for wildlife movement, the modeling approach employed here can be replicated in other biodiversity and ecological studies (e.g., hydrological research and forest research). Other landscape-level research that involves spatial modeling like urban/regional growth management, shared infrastructure planning can also benefit from this research.

Acknowledgments. The authors are grateful for funding and logistic support from the Calgary Regional Partnership, Glenbow Ranch Provincial Park (Alberta Parks) and the Miistakis Institute

\section{References}

Adriaensen, F., Chardon, J.P., De Blust, G., Swinnen, E., Villalba, S., Gulinck, H. and Matthysena. E. (2003). The application of 'leastcost' modeling as a functional landscape model. Landscape and Urban Planning, 64, 233-247. https://doi.org/10.1016/S0169-2046 (02)00242-6

Ahuja, R.K., Magnanti, T.L. and Orlin, J.B. (1993). Network Flows: Theory, Algorithms, and Applications. Englewood Cliffs, New Jersey: Prentice-Hall.

Alberta Biodiversity Monitoring Institute. (2010). Human Footprint Data. Edmonton.

Avon, C. and Bergès, L. (2016). Prioritization of habitat patches for landscape connectivity conservation differs between least-cost and resistance distances. Landscape Ecology, 31(7), 1551-1565. https:// doi.org/10.1007/s10980-015-0336-8

Baguette, M., Blanchet, S., Legrand, D., Stevens, V.M. and Turlure, C. (2013). Individual dispersal, landscape connectivity and ecological networks. Biological Reviews, 88(2), 310-326. https://doi.org/1 0.1111/brv. 12000
Bailey, S. (2007). Increasing connectivity in fragmented landscapes: An investigation of evidence for biodiversity gain in woodlands. Forest Ecology and Management, 238, 7-10. https://doi.org/10.10 16/j.foreco.2006.09.049

Beier, P., Majka, D.R. and Newell, S.I. (2009). Uncertainty analysis of least-cost modeling for designing wildlife linkages. Ecological Applications, 19(8), 2067-2077. https://doi.org/10.1890/08-1898.1

Bekoff, M. and Wells, M. (1986). Social ecology and behavior of coyotes. Advances in the Study of Behavior, 16, 251-338. https://doi.org/ 10.1016/S0065-3454(08)60193-X

Brandes, U. and Erlebach, T. (2005). Network Analysis: Methodological Foundation. New York: Springer.

Cadavid-Florez, L., Laborde, J. and Mclean, D.J. (2020). Isolated trees and small woody patches greatly contribute to connectivity in highly fragmented tropical landscapes. Landscape and Urban Planning, 196, 103745. https://doi.org/10.1016/j.landurbplan.2020.103745

Calgary Regional Partnership. (2012). Calgary Metropolitan Plan. Calgary Regional Partnership, Calgary.

Carroll, C., McRae, B. and Brookes, A. (2012). Use of linkage mapping and centrality analysis across habitat gradients to conserve connectivity of gray wolf populations in western North America. Conservation Biology, 26, 78-87. https://doi.org/10.1111/j.1523-1739.201 1.01753.x

Cavallini, P. (1996). Variation in the social system of the red fox. Ethology Ecology \& Evolution, 8, 323-342.

Clevenger, A.P. and Waltho, N. (2005). Performance indices to identify attributes of highway crossing structures facilitating movement of large mammals. Biological Conservation, 121, 453-464. https://doi. org/10.1016/j.biocon.2004.04.025

Daily, G.C., Alexander, S., Ehrlich, P.R., Goulder, L., Lubchenco, J., Matson, P.A., Mooney, H.A., Postel, S., Schneider, S.H., Tilman, D. and Woodwell, G.M. (1997). Ecosystem services: Benefits supplied to human societies by natural ecosystems. Issues in Ecology, $2,1-18$.

Forman, R.T.T. and Godron, M. (1986). Landscape Ecology. New York: Jhon Wily \& Sons.

Freeman, L.C., Borgatti, S.P. and White, D.R. (1991). Centrality in valued graphs: A measure of betweenness based on network flow. Social Networks, 13, 141-154. https://doi.org/10.1016/0378-8733(91) 90017-N

Galpern, P., Manseau, M. and Fall, A. (2011). Patch-based graphs of landscape connectivity: A guide to construction, analysis and application for conservation. Biological Conservation, 144(1), 44-55. https://doi.org/10.1016/j.biocon.2010.09.002

Gerlach, D., Atwater, S. and Schnell, J. (1994). The Wildlife Series: Deer. Mechanicsburg: Stackpole books.

Girardet, X., Conruyt-Rogeon, G. and Foltête, J.C. (2015). Does regional landscape connectivity influence the location of roe deer roadkill hotspots? European Journal of Wildlife Research, 61(5), 731742. https://doi.org/10.1007/s10344-015-0950-4

Giulio, M.D., Holderegger, R. and Tobias, S. (2009). Effects of habitat and landscape fragmentation on humans and biodiversity in densely populated landscapes. Journal of Environmental Manage-ment, 90, 2959-2968. https://doi.org/10.1016/j.jenvman.2009.05.002

Government of Alberta. (2014). Alberta Land-use Integrated Plan: South Saskatchewan Regional Plan 2014-2024. Edmonton.

Government of Canada. (2000). Canada National Parks Act. http://lawslois.justice.gc.ca/eng/acts/n-14.01/page-1.html

Gurrutxaga, M. and Saura, S. (2014). Prioritizing highway defragmentation locations for restoring landscape connectivity. Environmental Conservation, 41(2), 157-164. https://doi.org/10.1017/S037689291 3000325

Hansen, A.J., Knight, R.L., Marzluff, J.M., Powell, S., Brown, K., Gude, P.H. and Jones, K. (2005). Effects of exurban development on biodiversity: Patterns, mechanisms, and research needs. Ecological Applications, 15(6), 1893-1905. https://doi.org/10.1890/05-5221 
Harrison, S., Stahl, A. and Doak, D. (1993). Spatial models and spotted owls: Exploring some biological issues behind recent events. Conservation Biology, 7(4), 950-953. https://doi.org/10.1046/j.152 3-1739.1993.740950.x

Hobbs, T.N., Galvin, K.A., Stokes, C.J., Lackett, J.M., Ash, A.J., Boone, R.B., Reid, R.S. and Thornton, P.K. (2008). Fragmentation of rangelands: Implications for humans, animals, and landscapes. Global Environmental Change, 18, 776-785. https://doi.org/10.101 6/j.gloenvcha.2008.07.011

Huber, P.R., Shilling, F., Thorne, J.H. and Greco, S.E. (2012). Municipal and regional habitat connectivity planning. Landscape and $U r$ ban Planning, 105(1-2), 15-26. https://doi.org/10.1016/j.landurbpla n.2011.11.019

Jenks, G.F. (1967). The data model concept in statistical mapping. International Yearbook of Cartography, 7, 186-190.

Jepsen, J.U., Baveco, J.M., Topping, C.J., Verboom, J. and Vos, C.C. (2004). Evaluating the effect of corridors and landscape heterogeneity on dispersal probability: A comparison of three spatially explicit modeling approaches. Ecological Modelling, 181, 445-459. https:// doi.org/10.1016/j.ecolmodel.2003.11.019

Koen, E.L., Bowman, J., Sadowski, C. and Walpole, A.A. (2014). Landscape connectivity for wildlife: Development and validation of multispecies linkage maps. Methods in Ecology and Evolution, 5(7), 626-633. https://doi.org/10.1111/2041-210X.12197

Lindenmayer, D.B. and Fischer, J. (2006). Tackling the habitat fragmentation panchreston. Trends in Ecology and \& Evolution, 22(3), 127-132. https://doi.org/10.1016/j.tree.2006.11.006

Lynch, G.M. and Morgantini, L.E. (1984). Sex and age differential in seasonal home range of moose in northwestern Alberta. Alces, 20, 61-78.

Marrotte, R.R. and Bowman, J. (2017). The relationship between leastcost and resistance distance. PLOS ONE, 12(3), 1-19. https://doi. org/10.1371/journal.pone.0174212

Merriam, G. (1984). Connectivity: A fundamental ecological characteristic of landscape pattern. In: Brandt, J. and Agger, P. Proceedings of the 1st international seminar on methodology in landscape ecological research and planning. Denmark: Roskilde University.

Millenium Ecosystem Assessment. (2003). Millennium Ecosystem Assessment: A Framework for Assessment. Washington, DC: Island Press.

Mitchell, M.G.E., Bennett, E.M. and Gonzalez, A. (2013). Linking landscape connectivity and ecosystem service provision: Current knowledge and research gaps. Ecosystems, 16, 894-908. https://doi. org/10.1007/s 10021-013-9647-2

Newman, M.E.J. (2005). A measure of betweenness centrality based on random walks. Social Networks, 27, 39-54. https://doi.org/10. 1016/j.socnet.2004.11.009

Olsson, M.P.O., Widén, P. and Larkin, J.L. (2008). Effectiveness of a highway overpass to promote landscape connectivity and movement of moose and roe deer in Sweden. Landscape and Urban Planning, 85(2), 133-139. https://doi.org/10.1016/j.landurbplan. 2007.10.006

Peterson, R.L. (1950). A new species of moose from North America. Occasional Papers of the Royal Ontario Museum, 9, 1-17.

Petsas, P., Tsavdaridou, A.I. and Mazaris, A.D. (2020). A multispecies approach for assessing landscape connectivity in data-poor regions. Landscape Ecology, 35(3), 561-576. https://doi.org/10.1007/s1098

\section{0-020-00981-2}

Quinn, M.S., Poujol, P.C.P., Tyler, M.E. and Chernoff, G. (2014). Modeling a rapidly urbanizing regional landscape to assess connectivity of natural integrity for ecological flows. Spaces and Flows: An International Journal of Urban and ExtraUrban Studies, 4, 71-83.

Rudnick, D.A., Ryan, S.J., Beier, P., Cushman, S.A., Dieffenbach, F., Epps, C.W., Gerber, L.R., Hartter, J., Jenness, J.S., Kintsch, J., Merenlender, A.M., Perkl, R.M., Preziosi, D.V. and Trombulak, S.C. (2012). The role of landscape connectivity in planning and implementing conservation and restoration priorities. Issues in Ecology, (16), 1-23.

Scolozzi, R. and Geneletti, D. (2012). A multi-scale qualitative approach to assess the impact of urbanization on natural habitats and their connectivity. Environmental Impact Assessment Review, 36, 9-22. https://doi.org/10.1016/j.eiar.2012.03.001

Spanowicz, A.G. and Jaeger, J.A.G. (2019). Measuring landscape connectivity: On the importance of within-patch connectivity. Landscape Ecology, 34(10), 2261-2278. https://doi.org/10.1007/s10980019-00881-0

Swingland, I.R. and Greenwood, P.J. (1983). The Ecology of Animal Movement. Oxford: Clarendon Press.

Taylor, P.D., Fahrig, L., Henein, K. and Merriam, G. (1993). Connectivity is a vital element of landscape structure. Oikos, 68, 571-573. https://doi.org/10.2307/3544927

Tischendorf, L. and Fahrig, L. (2000). On the usage and measurement of landscape connectivity. Oikos, 90, 7-19. https://doi.org/10.1034/ j.1600-0706.2000.900102.x

Urban, D. and Keitt, T. (2001). Landscape connectivity: A graph-theoretic perspective. Ecology, 82, 1205-1218. https://doi.org/10.23 07/ 2679983

Uusitalo, L., Lehikoinen, A., Helle, I. and Myrberg, K. (2015). An overview of methods to evaluate uncertainty of deterministic models in decision support, Environmental Modelling \& Software, 63, 24-31. https://doi.org/10.1016/j.envsoft.2014.09.017.

Van Der Grift, E.A., Van Der Ree, R., Fahrig, L., Findlay, S., Houlahan, J., Jaeger, J.A.G., Klar, N., Madrinan, L.F. and Olson, L. (2013). Evaluating the effectiveness of road mitigation measures. Biodiversity and Conservation, 22(2), 425-448. https://doi.org/10.1007/s1 0531-012-0421-0

Walter, W.D., VerCauteren, K.C., Campa, H., Clark, W.R., Fischer, J. W., Hygnstrom, S.E., Mathews, N.E., Nielsen, C.K., Schauber, E.M., Van Deelen, T.R. and Winterstein, S.R. (2009). Regional assessment on influence of landscape configuration and connectivity on range size of white-tailed deer. Landscape Ecology, 24(10), 14051420. https://doi.org/10.1007/s10980-009-9374-4

With, K.A., Gardner, R.H. and Turner, M.G. (1997). Landscape connectivity and population distributions in heterogeneous environments. Oikos, 78, 151-169. https://doi.org/10.2307/3545811

Zetterberg, A., Mörtberg, U.M. and Balfors, B. (2010). Making graph theory operational for landscape ecological assessments, planning, and design. Landscape and Urban Planning, 95, 181-191. https:// doi.org/10.1016/j.landurbplan.2010.01.002

Zhang, Z., Meerow, S., Newell, J.P. and Lindquist, M. (2019). Enhancing landscape connectivity through multifunctional green infrastructure corridor modeling and design. Urban Forestry and Urban Greening, 38, 305-317. https://doi.org/10.1016/j.ufug.2018.10. 014 